\title{
Consensus Protocol for the Treatment of Super-Refractory Status Epilepticus
}

\section{Protocolo de Consenso para o Tratamento do Estado de Mal Epiléptico Super-Refractário}

\author{
Daniel GOMES $\square^{1}$, José PIMENTEL², Carla BENTES², Diana AGUIAR DE SOUSA², Ana Patrícia ANTUNES², \\ António ALVAREZ ${ }^{3}$, Zélia Costa e SILVA ${ }^{3}$ \\ Acta Med Port 2018 Oct;31(10):598-605 - https://doi.org/10.20344/amp.9679
}

\section{ABSTRACT}

Introduction: Super-refractory status epilepticus is defined as status epilepticus that persists or recurs 24 hours after anaesthetic therapy onset or after its withdrawal. It is mostly found in intensive care units and carries high mortality but good long-term prognosis for those who survive. In contrast with the initial phases of status epilepticus, treatment lacks strong scientific evidence and is mostly derived from case reports or small case series.

Objective: To propose a protocol for the treatment of super-refractory status epilepticus in level III intensive care units, focusing on the treatment strategies to control clinical and/or electroencephalographic epileptic activity.

Material and Methods: Narrative review of the literature by PubMed search. Available evidence was discussed in consensus meetings by intensive care and neurology experts' from a level III intensive care unit and one of the Portuguese reference centres for the treatment of refractory epilepsy, respectively.

Results: Anaesthetics with the highest level of evidence are propofol, midazolam, thiopental and ketamine. These represent the basis of the treatment of super-refractory status epilepticus and should be used in combination with antiepileptic drugs. The level of evidence for the latter is lower, however, levetiracetam, topiramate, pregabalin, lacosamide, valproic acid, phenytoin and perampanel may be recommended. Alternative therapeutic strategies with very low level of evidence are recommended in cases of total absence of clinical response, such as magnesium sulphate, pyridoxine, ketogenic diet, therapeutic hypothermia and immunosupression.

Conclusion: We propose a treatment protocol based on a sequential combination of anaesthetics, anti-epileptic drugs and alternative therapies. Strategies to evaluate treatment response and to wean drugs based on clinical results are also proposed.

Keywords: Clinical Protocols; Consensus; Critical Care; Review Literature; Status Epilepticus

\section{RESUMO}

Introdução: O estado de mal epiléptico super-refractário define-se como um estado de mal epiléptico que persiste ou recorre 24 horas após o início da terapêutica anestésica ou após a sua suspensão. Encontra-se fundamentalmente em unidades de cuidados intensivos e está associado a uma elevada mortalidade apesar de ter um bom prognóstico a longo prazo nos doentes que sobrevivem. Ao contrário das fases iniciais do estado de mal epiléptico, o tratamento não é baseado numa forte evidência científica e deriva principalmente de relatos ou pequenas séries de casos.

Objectivo: Propor um protocolo de tratamento do estado de mal epiléptico super-refractário em unidades de cuidados intensivos de nível III, focando-se nas estratégias de tratamento para controlar a actividade epiléptica clínica e/ou electroencefalográfica.

Material e Métodos: Revisão narrativa da literatura no PubMed, seguida de discussão em reuniões de consenso de peritos de medicina intensiva e neurologia de uma unidade de cuidados intensivos de nível III e de um dos centros de referência para o tratamento da epilepsia refractária em Portugal, respectivamente.

Resultados: Os fármacos anestésicos com maior nível de evidência são o propofol, midazolam, tiopental e ketamina. Estes representam a base do tratamento do estado de mal super-refractário e devem ser utilizados em combinação com fármacos antiepilépticos. O nível de evidência para estes últimos é menor, contudo, podem ser recomendados o levetiracetam, topiramato, pregabalina, lacosamida, perampanel, ácido valpróico, fenitoína e perampanel. São recomendadas estratégias terapêuticas alternativas com muito baixo nível de evidência, em casos de ausência total de resposta clínica, tais como o sulfato de magnésio, piridoxina, dieta cetogénica, hipotermia terapêutica e imunossupressão.

Conclusão: Propomos um protocolo de tratamento baseado numa combinação sequencial de fármacos anestésicos, antiepilépticos e terapêuticas alternativas. São também propostas estratégias de avaliação da eficácia da terapêutica e de desmame farmacológico progressivo de acordo com a resposta clínica obtida.

Palavras-chave: Consenso; Cuidados Críticos; Mal Epiléptico; Protocolos Clínicos; Revisão da Literatura

\section{INTRODUCTION}

Status epilepticus (SE) is defined as a condition resulting either from the failure of the mechanisms responsible for seizure termination or from the initiation of mechanisms which lead to abnormally prolonged seizures (after time point $\mathrm{t} 1$ ). It is a condition that can have long-term consequences (after time point t2), including neuronal death, neuronal injury, and change of neuronal networks, depending on the type and duration of seizures. It can be classified according to its semiology (presence or absence of prominent motor symptoms and the degree of impaired

1. Serviço de Medicina I. Hospital de Santa Maria. Centro Hospitalar Lisboa Norte. Lisboa. Portugal.

2. Departamento de Neurociências. Centro de Referência de Epilepsia Refractária. Hospital de Santa Maria. Centro Hospitalar Lisboa Norte. Lisboa. Portugal.

3. Serviço de Medicina Intensiva. Hospital de Santa Maria. Centro Hospitalar Lisboa Norte. Lisboa. Portugal.

$\triangle$ Autor correspondente: Daniel Gomes. danielccgomes@gmail.com

Recebido: 04 de novembro de 2017 - Aceite: 29 de maio de 2018 | Copyright @ Ordem dos Médicos 2018 
consciousness), etiology, electroencephalogram correlates and age. ${ }^{1}$

Generalized convulsive status epilepticus (GCSE) is classically defined as a continuous generalized tonic-clonic seizure (GTCS) that lasts for at least five minutes or a series of recurrent GTCS without complete consciousness recovery. $^{2}$

When treatment of GCSE is delayed or insufficient, it can evolve to a state of progressive electromechanical dissociation, characterized by coma and subtle involuntary movements or absence of motor activity with persistent electroencephalographic activity, a condition named subtle status epilepticus (SSE). ${ }^{3,4}$

Failure of the physiologic mechanisms to abort an isolated seizure due to either persistent excitatory or failure of inhibitory activities is the basic physiopathology of SE. Associated mechanisms are still largely unknown but seem to influenced by the aetiology. ${ }^{5}$ Despite the cause, persistent epileptic activity induces early changes in neurotransmitter traffic. Evidence suggests that there is a reduction in the expression of inhibitory gamma-aminobutyric acid type A receptors $\left(G_{A B A}\right)$ and over-expression of N-methyl-Daspartate receptors. This justifies the progressive loss of benzodiazepines efficacy. ${ }^{6}$ The GCSE that lasts for 30 to 45 minutes can cause glutamate excitotoxicity mediated neuronal lesion, especially In limbic structures such as the hippocampus. Moreover, systemic complications associated with SE, such as hyperthermia, hypoxia or hypotension further aggravate the degree of neuronal lesion (secondary lesion). ${ }^{5}$

Treatment should be started during pre-hospital care (when possible) and the emergency room setting (phase I). Benzodiazepines in intermittent boluses are the first line therapy in this phase. If seizures persist (phase II), intravenous boluses of antiepileptic drugs (AEDs) should be started. Monotherapy is firstly indicated but a second AED should be associated if seizures persist. Reversible causes should be immediately searched and corrected. ${ }^{2}$

If clinical and/or electroencephalographic epileptic activity persists despite two appropriately selected and dosed antiepileptic drugs, patient is considered to be in refractory status epilepticus (RSE). ${ }^{7}$ Different treatment strategies are advocated depending on the clinical form. For patients with GCSE there is immediate indication for general anaesthesia and confirmation of complete seizure remission by electroencephalography (EEG) ('burst-suppression' pattern). Admission to an intensive care unit (ICU) is recommended. ${ }^{2,7}$ EEG is a decisive complementary test in diagnostic evaluation, evolution, prognosis and therapeutic decision, but there are currently no evidence-based EEG criteria for SE. Therefore, EEG pattern is out of the scope of this article. ${ }^{1}$

For patients without consciousness impairment, an alternative approach with AEDs in continuous infusion and/or association with other AEDs may be adopted. In fact, there is evidence that general anaesthetic drugs may be associated with increased mortality. Therefore, only patients who are refractory to these approaches should be considered for general anaesthesia. ${ }^{7,8}$

In about $15 \%$ of patients who are treated for RSE, clinical and/or electroencephalographic epileptic activity persists 24 hours after introduction of anaesthetic therapy or recurs after its suspension. These are the currently used criteria to define super-refractory status epilepticus (SRSE). ${ }^{9}$ It is more frequent in patients with central nervous system acute lesions or in patients without previous epilepsy history and with no apparent aetiology. Mortality becomes higher, varying between $23 \%$ - 48\%. However, published series report that about half to one third of surviving patients experience good long-term recovery. ${ }^{10-12}$

Several neuronal events, incompletely understood, may justify the persistent epileptic activity. Proposed hypothesis include reduction in the number of functional $\mathrm{GABA}_{\mathrm{A}}$ receptors, upregulation of glutamatergic receptors, mitochondrial failure, pro-inflammatory activity and blood-brain barrier increased permeability. ${ }^{13-16}$

In contrast to the initial phases of SE, it is not known whether seizure control beyond a 24 hour period contributes to the reduction of excitotoxicity mediated lesions. Furthermore, SRSE treatment lacks strong scientific evidence and therefore is an area of great debate.

Current clinical practices in the treatment of SRSE in ICUs are mostly guided by the centre experience and available therapies. There are no published guidelines and scientific evidence is only based on case reports or small case series.

It is generally accepted that common therapeutic objectives in SRSE are:

1. Abort clinical and electroencephalographic epileptic activity;

2. Neuroprotection;

3. Avoid and treat systemic complications of coma and prolonged sedation.

\section{OBJECTIVE}

The aim of this article is to propose a treatment protocol for adult patients with SRSE evolving from GCSE or SSE, focusing on the strategies to abort clinical and electroencephalographic epileptic activity. We first review available evidence and then propose an expert consensus-based protocol that was designed to be applied in level III ICUs.

\section{MATERIAL AND METHODS}

A narrative review of the literature was performed by searches on PubMed using the terms 'status epilepticus', 'refractory status epilepticus' and 'super-refractory status epilepticus'. Thirty-four articles (case reports, case series, guidelines, meta-analysis and population-based studies) published from 1998 to 2015 were selected. A provisional protocol was created and discussed by intensive care specialists from a level III ICU in a consensus meeting. This protocol was then reviewed by a group of neurology specialists, including one neurophysiologist, from one of the Portuguese reference centres for the treatment of refractory 
epilepsy in consensus meetings. Obtained statements were subject to a review from intensive care specialists and a final protocol was established. This protocol was approved by the local Pharmacy and Therapeutics committee.

\section{RESULTS}

Super-refractory status epilepticus treatment - state of the art evidence review

\section{Cause identification}

The main measure that influences prognosis of SRSE remains cause identification and treatment. ${ }^{17}$ Most cases are due to a severe acute lesion (trauma, infection or stroke) which is immediately apparent from clinical history or imaging studies. There are, however, a variety of less frequent causes such as immunological, inherited metabolic diseases, less frequent infections, toxins and genetic diseases. ${ }^{16}$ Lastly, there is a controversial group of patients without previous epilepsy history with no identified cause known as NORSE ('new onset refractory status epilepticus'). This classification may be erroneous because these patients may have an underlying unrecognized or unknown cause.

\section{Therapeutic lines}

\section{Anaesthetic agents}

There is a universal consensus that general anaesthesia is the central treatment of SRSE. However, there are no clinical trials demonstrating superiority of any agent over another. Choice should be based on centre or clinician experience or on the most favourable adverse effects profile. The objective is to reach a level of anaesthesia corresponding to a 'burst-suppression' EEG pattern and maintain it for at least 24 hours. Anaesthetic weaning should be slow, preferentially during 24 hours. If epileptic activity recurs during or after weaning, the previous sedation level should be attained but for progressively longer periods which may be as long as five days. ${ }^{18}$

The three most used anaesthetic agents are propofol, midazolam and thiopental. A recent systematic review suggests that thiopental titrated to attain EEG activity suppression may have a slight increased efficacy over propofol or midazolam in RSE with less seizure recurrence after sedation weaning, despite increased hemodynamic instability and unchanged mortality. ${ }^{19}$ Ketamine is an alternative anaesthetic agent that has shown favourable results in some case series. ${ }^{20}$

Propofol - Propofol is a short-acting anaesthetic agent with a short onset of action and a short half-life. Due to its pharmacokinetic properties, it has a great control over the level of anaesthesia. The main disadvantages are the vasoplegic effect and the risk of propofol infusion syndrome (PRIS). Young age, administration during prolonged periods and/or in high doses or the concomitant use of corticosteroids are risk factors for PRIS. An induction dose of 1 - 2 $\mathrm{mg} / \mathrm{kg}$ and maintenance dose of $30-200 \mathrm{mcg} / \mathrm{kg} / \mathrm{min}$ are recommended. 2,21
Midazolam - Midazolam is an anaesthetic agent with a potent anti-epileptic effect and a short half-life. The main disadvantages are the need of progressively higher doses (tachyphylaxis), sometimes during the first 24 hours of administration, and the vasoplegic effect. Caution should be used in patients with hepatic or kidney failure due to its slower metabolism and excretion. An induction dose of 0.2 $\mathrm{mg} / \mathrm{kg}$ and maintenance dose of $0.05-2 \mathrm{mg} / \mathrm{kg} / \mathrm{h}$ are recommended..$^{2,21}$

Thiopental - Thiopental and other intravenous barbiturates have a potent anti-epileptic effect, reduce intracranial pressure and have potential neuroprotection effects. This has to be weighed against barbiturate long elimination time secondary to its lipophilic nature, the tachyphylaxis the vasoplegic effects, the pharmacologic interactions and other toxic adverse effects. An induction dose of $2-7 \mathrm{mg} /$ $\mathrm{kg}$ and maintenance dose of $0.5-5 \mathrm{mg} / \mathrm{kg} / \mathrm{h}$ are recom-

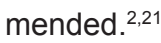

Ketamine - Ketamine is an anaesthetic agent with NMDA receptor antagonist activity with some advantages over conventional anaesthetics. It is devoid of the vasoplegic effect and is potentially neuroprotective due to its NMDA antagonist effect. ${ }^{21}$ Ketamine efficacy in SRSE has been reported in about 40 cases, in most of which it was coadministrated with another anaesthetic agent and/ or AED. Response was more likely when it was started during the initial phase of SRSE (during the first eight days) and when maintenance doses were greater than $0.9 \mathrm{mg} / \mathrm{kg} / \mathrm{h} .^{20,22}$

Recommended doses are $0.5-4.5 \mathrm{mg} / \mathrm{kg}$ for induction and $0.9-5 \mathrm{mg} / \mathrm{kg} / \mathrm{h}$ for maintenance. Reported adverse events are hypertension, which is rare due to the concomitant administration of other vasoplegic anaesthetics, and there has been a case report of late-onset encephalopathy with uncertain causality ${ }^{23}$.

\section{Anti-epileptic drugs}

In contrast to the initial phases of SE, there are no clinical trials showing the efficacy or benefit of AEDs in RSE or SSE, where anaesthetics play the main role. However, these drugs are generally used to allow for anaesthetics weaning and to avoid seizure recurrence.

In the absence of comparative studies, a combination therapy of no more than three AEDs is recommended, in the maximum tolerated dose, preferably with a predictable pharmacokinetic profile and with the least pharmacologic interactions and adverse effects. There are only published data regarding the use of levetiracetam (LEV), topiramate (TPM), pregabaline (PGB), lacosamide (LCM) and perampanel (PER) in RSE and SRSE, but these are limited to small case series. ${ }^{18,24,25}$ However, there is a good body of evidence favouring the use of other AEDs, such as valproic acid (VPA), phenytoin (PHT) and phenobarbital (PHB), in earlier SE phases. Therefore, if these were started in previous SE phases, it may be legitimate to maintain them in SRSE. Recently, a cohort study has shown that oral 
phenobarbital in association with thiopental sedation has allowed for a successful anaesthetic weaning. ${ }^{26}$

\section{Selected alternative therapies}

Alternative therapies have been used with variable reported efficacy when all 'conventional' therapies fail to control clinical or electroencephalographic epileptic activity. Evidence is mostly derived from case reports or small case series. Alternative treatment strategies that have the most favourable benefit/risk ratio or show a higher level of evidence and are easily available in any centre are described below. Other treatments, such as electroconvulsive therapy, other forms of stimulation and surgery are generally limited to a few treatment centres and therefore are out of the scope of this review.

Magnesium sulphate - There is a large experience with magnesium sulphate infusion in the treatment of seizures of eclampsia. Besides hypomagnesemia, there are only isolated case reports of its successful use in SRSE. However, its administration is relatively harmless and only contraindicated in severe kidney failure (creatinine clearance below $30 \mathrm{ml} / \mathrm{min}$ ), acute myocardial infarction and cardiac arrhythmias. In the reported cases, an initial dose of $4 \mathrm{~g}$ followed by a continuous infusion at a rate of $2-6 \mathrm{~g} / \mathrm{h}$ aiming for plasma levels of $3.5 \mathrm{mmol} / \mathrm{L}$ were used. ${ }^{27}$

Pyridoxine - Pyridoxine administration may be curative in the rare cases of inborn errors of pyridoxine metabolism and also in some acquired deficiencies, such as pregnancy and isoniazid use. Since its administration is secure and devoid of side effects, its routine use may be advocated in SRSE. Usual doses are $100-200 \mathrm{mg} /$ day and maximum recommended doses are $500-600 \mathrm{mg} /$ day. ${ }^{18}$

Immunosuppression - Immunosuppression in SRSE is based on two main pathophysiological premises. There is a growing body of evidence that proves the involvement of inflammatory mechanisms in the epileptogenic focus. ${ }^{28}$ Secondly, one cannot completely rule out the possibility of an underlying undiagnosed autoimmune disease, when all other aetiologies have been excluded. It has been used as an empirical treatment in some case reports, although it has been effective in only $5 \% .^{18}$

The most frequent regimens include a three day course of high dose methylprednisolone ( $1 \mathrm{~g} /$ day) followed by a five day course of intravenous immunoglobulin $(0.4 \mathrm{~g} / \mathrm{kg} / \mathrm{day})$ and then by a week of oral corticosteroid therapy $(1 \mathrm{mg} / \mathrm{kg} /$ day of prednisolone) which may be continued thereafter if a clinical response is achieved. A course of plasmapheresis may be used in alternative to intravenous immunoglobulin. Given the need for a prompt clinical answer in SRSE, the simultaneous association of methylprednisolone and intravenous immunoglobulin or plasmapheresis may be considered.

Risks are evident, particularly in terms of infectious complications and secondary effects of prolonged cortico- steroid therapy. The association of high dose corticosteroid therapy and intravenous immunoglobulin also increases the risk of thrombotic complications. ${ }^{29}$

Therapeutic hypothermia - Hypothermia has demonstrated favourable anti-epileptic effects in experimental models and clinical efficacy has been reported in some isolated cases of SRSE. Conceptually, it allows for a reduction in cerebral metabolic activity, ATP consumption, mitochondrial dysfunction, glutamatergic activity, reactive oxygen species production and oxidative stress. Moreover, its benefit in neuroprotection after cardiac arrest has been demonstrated in several clinical trials. ${ }^{30}$ In the reported cases, a target central temperature of 32 to 35 Celsius degrees was maintained during $24-48$ hours. Significant complications can, however, limit the use of this therapeutic approach such as shivering (which may require muscle relaxants), hydro-electrolytic and acid-base disorders, coagulopathy, infections, pressure ulcers, cardiac arrhythmias and reduction of drug clearance. ${ }^{31}$

Ketogenic diet - Ketogenic diet has historically been used to treat refractory epilepsy in childhood. ${ }^{32}$ Promising results in adults with SRSE were reported recently in a case series. It was effective in $90 \%$ of patients as a last resort therapy, in a median of three days after ketosis was established..$^{33}$ Classical ketogenic diet with high fat and low carbohydrate (ratio 4:1) was initially maintained but half of the patients transitioned successfully to a modified Atkins diet after SRSE control. These diets are possible to establish in intubated patients using specific commercial enteral formulations that are administered through gastric tubes. Ketosis confirmation should preferentially be done with blood betahydroxybutyrate levels determination, aiming for a target of $3.0 \mathrm{mmol} / \mathrm{L}^{34}$

The most frequent complication is hypoglycaemia so frequent glycaemia monitoring is required (every three hours) in the first three days and then every six hours. An Intravenous bolus of glucose should be used to treat hypoglycaemia but continuous infusion should be avoided since it will stop ketosis. Simultaneous administration of propofol significantly increases the risk of PRIS and corticosteroids may inhibit ketogenesis so they should be avoided.

\section{Protocol for the treatment of super-refractory status epilepticus}

Admission to intensive care unit

Admission to ICU is mandatory in patients with RSE who are candidates for anaesthetic therapy. A specific protocol for the treatment of RSE should initially be used and must follow these general principles:

1. The 'Burst-suppression' EEG pattern must be confirmed as soon as possible. Continuous EEG monitoring available in the ICU can be used alternatively but specific therapeutic decisions should not be based on it (e.g. AED weaning and switching);

2. When EEG is not immediately available, a continuous 
and constant dose of anaesthetic that aborts clinical seizures should be maintained until it is performed;

3. The 'burst-suppression'” pattern should be maintained for at least 24 hours and confirmed by a second EEG performed 24 hours after anaesthesia induction;

4. Progressive anaesthetic dose reduction (anaesthetic weaning) should be performed during a 24 hour period;

5. AEDs started in the initial phase of SE should be maintained in constant doses and, when applied, in therapeutic levels. Weaning should not be tried in this acute phase.

Specific protocols for the treatment of RSE are available elsewhere and are out of the scope of this article. ${ }^{1,3}$

\section{Diagnostic criteria}

Patient is considered to be in SRSE when at least one of the following criteria is met:

- Continuous epileptic activity for at least 24 hours after anaesthesia induction;

- Recurrent epileptic activity 24 hours after anaesthesia induction;

- Recurrent epileptic activity after anaesthetic weaning. Weaning has to be performed according to the aforementioned stated general principles.

SE maintenance is defined as persistent epileptiform discharges in a burst-suppression pattern in sedated patients.

\section{Treatment protocol}

We recommend the following protocol for the treatment of patients with SRSE that evolves from GCSE or SSE:

1. Identify and treat the cause of SE;

2. Start thiopental in recommended dose and progressively wean the previous anaesthetic during the following 24 hours;

3. Maintain the two previously started AEDs in the maximum tolerated doses;

4. Associate a third AED in the maximum tolerated dose (consider the association of AEDs with less pharmacologic interactions and with the most favourable adverse events profile):

a. Phenytoin (IV route, $20 \mathrm{mg} / \mathrm{kg}$ initial dose, $3-5$ $\mathrm{mg} / \mathrm{kg} /$ day maintenance dose);

b. Valproic acid (IV route, $20-40 \mathrm{mg} / \mathrm{kg}$ initial dose, $1-5 \mathrm{mg} / \mathrm{kg} / \mathrm{h}$ maintenance dose);

c. Levetiracetam (IV route, $500-1500 \mathrm{mg}$ bid);

d. Topiramate (oral route, $500 \mathrm{mg}$ bid for 2 to 5 days and then progressively wean to $200 \mathrm{mg}$ bid);

e. Lacosamide (IV route, initial bolus of $200-400$ $\mathrm{mg}$ and maintenance dose of $100-300 \mathrm{mg} \mathrm{bid}$ );

f. Perampanel (oral route, initial dose of $4 \mathrm{mg} \mathrm{ti-}$ trated to a maximum dose of $12 \mathrm{mg}$ od in daily increments of $2-4 \mathrm{mg}$ );

5. Only three AEDs should be maintained in this phase. If other AEDs were started in previous SE phases they should be progressively weaned along several days;
6. If SE recurs after thiopental weaning, having previously achieved a burst-suppression EEG pattern without epileptic activity during 24 hours under this anaesthetic, weaning should again be tried with the association of phenobarbital in therapeutic dose and one of the previous AEDs should be weaned along several days;

7. If SRSE persists under thiopental anaesthesia (epileptiform discharges) or if it recurs after thiopental weaning in association with phenobarbital, then ketamine should be associated with thiopental in recommended dose;

8. Patient should be maintained in 'burst-suppression' during consecutive 24 hour cycles of anaesthetics: 24 hours under propofol or midazolam; 24 hours under thiopental; 24 hours under thiopental and ketamine;

9. Progressively longer periods of sedation should be considered if SRSE persists or recurs;

10. An EEG should be performed as soon as possible and 24 hours after each anaesthetic therapy adjustment (anaesthetic induction, suspension or association) to exclude epileptic activity;

11. Each anaesthetic should be weaned gradually along 24 hours until complete suspension;

12. Simultaneous weaning of two anaesthetics is not recommended;

13. If SRSE persists or recurs despite all previous recommendations have been followed, then the patient should be maintained in 'burst-suppression' under combined anaesthesia with thiopental and ketamine, and all of the following therapeutics should be associated:

a. Magnesium sulphate - Intravenous bolus (4 g) followed by a continuous infusion (2 - $6 \mathrm{~g} / \mathrm{h}$ ) aiming for plasma levels of $3.5 \mathrm{mmol} / \mathrm{L}$;

b. Pyridoxine - 100 - 600mg daily oral dose;

c. One of the following alternative therapies, chosen case-by-case according to possible aetiology and adverse effects profile:

I. Immunosuppression (refer to specific protocol below);

II. Therapeutic hypothermia (follow the usual specific protocol of the intensive care unit);

III. Ketogenic diet (refer to specific protocol below);

14. If SRSE remains refractory despite all the previous measures, other alternative measures should be considered: vagus nerve stimulation, electroconvulsive therapy, trigeminal nerve stimulation, transcranial magnetic stimulation, epilepsy surgery.

\section{Immunosuppression protocol}

1. Exclude active infection, including central nervous system;

2. Evaluate cerebrospinal fluid inflammatory parameters and blood-brain barrier permeability index; 
3. Associate:

a. Intravenous methylprednisolone (1 g/day) during 3 - 5 days;

b. Intravenous immunoglobulin (0.4 g/kg/day) or plasmapheresis during five days;

4. After the initial methylprednisolone course, maintain oral prednisolone (1 $\mathrm{mg} / \mathrm{kg} / \mathrm{day})$ during eight days and eventually thereafter if clinical response is achieved;

5. Maintain the 'burst-suppression' pattern during immunosuppression course for a period of time that should be adjusted to each particular case based on the remaining clinical picture, adverse effects and EEG pattern

\section{Ketogenic diet protocol}

1. Stop ongoing enteral feed and continuous intravenous glucose infusions;

2. Initiate a specific enteral formulation (commercial or prepared by the hospital) for ketogenic diet considering daily caloric, protein, vitamins and water needs;

3. The classical ketogenic diet should be the initial chosen dietetic regimen:

4. Ketosis should be confirmed by plasma levels,

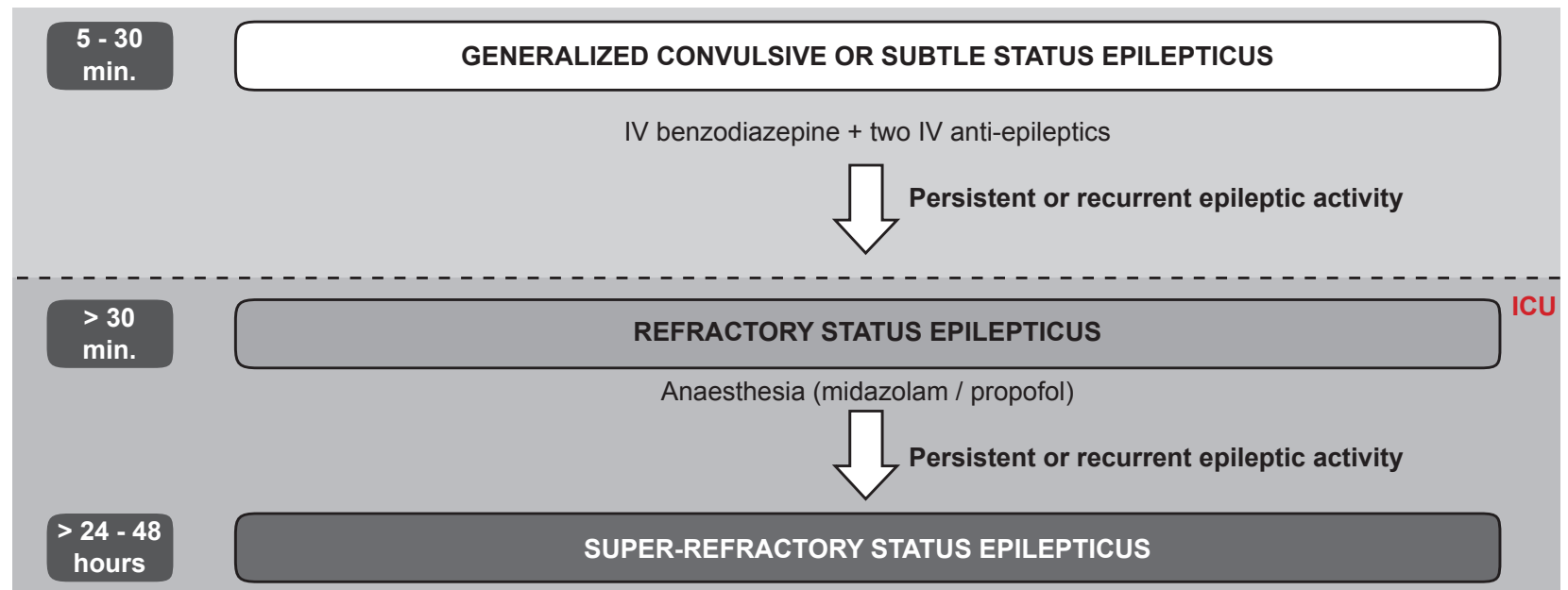

SWITCH ANAESTHETIC TO THIOPENTAL + THIRD ANTI-EPILEPTIC

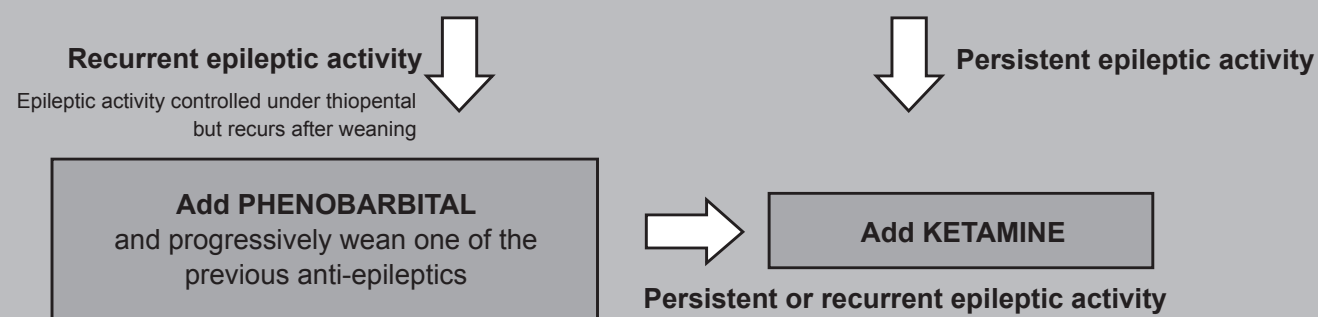

Persistent or recurrent epileptic activity

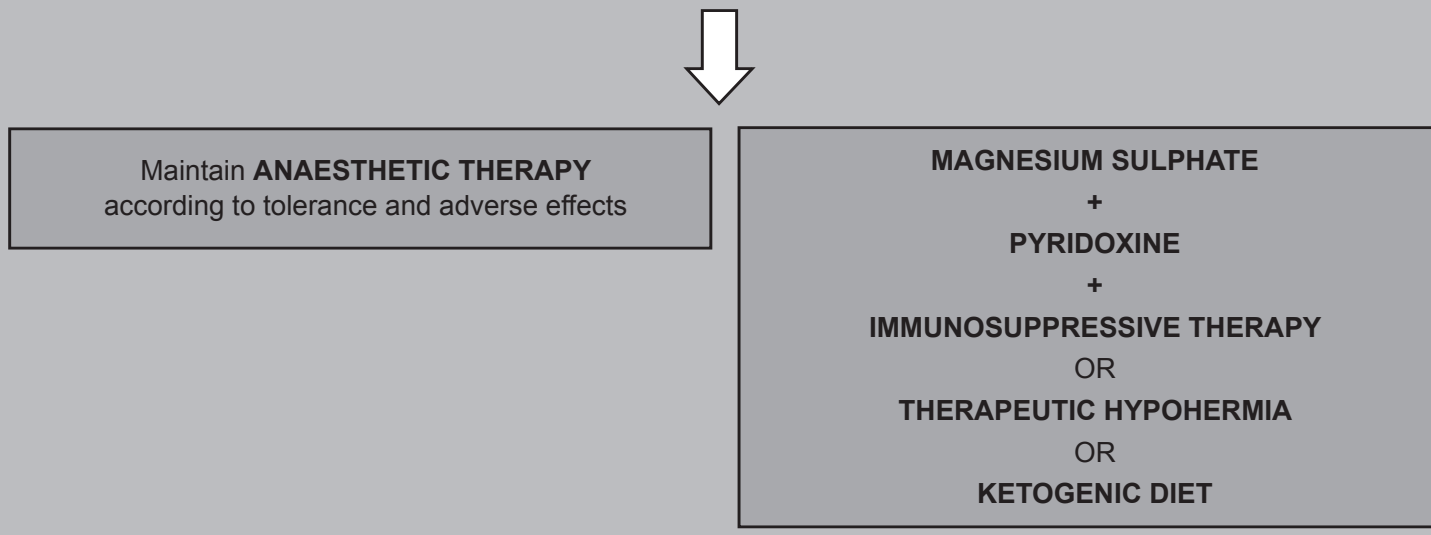

Figure 1 - Flowchart for the treatment of super-refractory status epilepticus (refer to Conclusions for an explanation). An EEG should be performed at least 24 hours after every therapeutic change (anaesthetic and/or anti-epileptic) to confirm the 'burst-suppression' pattern. 
aiming for a target of $3.0 \mathrm{mmol} / \mathrm{L}$;

5. Glycaemia should be monitored every three hours in the first three days and then every six hours:

a. Administer intravenous hypertonic dextrose $(30 \%)$ in the case of hypoglycaemia;

6. Acid-base disorders should be corrected with exogenous sodium bicarbonate (oral or intravenous);

7. Maintain ketogenic diet for at least three days after ketosis induction, before starting to wean anaesthetics;

8. If a clinical response is achieved, then the patient may be switched to an alternative less restrictive ketogenic dietetic regimen, such as Modified Atkins;

9. Propofol and corticosteroids should be avoided, due to the risks of PRIS and ketosis inhibition, respectively.

\section{CONCLUSION}

Patients with persistent or recurrent SE for more than 24 hours after anaesthesia onset or with SE that recurs during or after anaesthetics' weaning are considered to fulfil criteria for SRSE (Fig. 1). We recommend that anaesthetic therapy should be switched to thiopental and a third AED should be associated. An EEG should be performed as soon as possible to confirm the 'burst-suppression' pattern. This combination therapy should be maintained in stable doses for a period of 24 hours, after which another EEG

\section{REFERENCES}

1. Trinka E, Cock H, Hesdorffer D, Rossetti AO, Scheffer IE, Shinnar S, et al. A definition and classification of status epilepticus - report of the ILAE Task Force on Classification of Status Epilepticus. Epilepsia. 2015;56:1515-23.

2. Brophy GM, Bell R, Claassen J, Alldredge B, Bleck TP, Glauser T, et al. Neurocritical Care Society Status Epilepticus Guideline Writing Committee. Guidelines for the evaluation and management of status epilepticus. Neurocrit Care. 2012;17:3-23.

3. Shorvon S, Trinka E. Nonconvulsive status epilepticus and the postictal state. Epilepsy Behav. 2010;19:172-5.

4. Meierkord H, Boon P, Engelsen B, Göcke K, Shorvon S, Tinuper P, et al. European Federation of Neurological Societies. EFNS guideline on the management of status epilepticus in adults. Eur J Neurol. 2010;17:34855.

5. Lowenstein DH, Alldredge BK. Status epilepticus. N Engl J Med. 1998;338:970-6.

6. Naylor DE. Treating acute seizures with benzodiazepines: does seizure duration matter? Epileptic Disord. 2014;16:69-83.

7. Hocker S, Tatum WO, LaRoche S, Freeman WD. Refractory and superrefractory status epilepticus - an update. Curr Neurol Neurosci Rep. 2014;14:452.

8. Sutter R, Marsch S, Fuhr P, Kaplan PW, Ruegg S. Anesthetic drugs in status epilepticus: risk or rescue?: A 6-year cohort study. Neurology. 2014;82:656-64.

9. Shorvon S. Super-refractory status epilepticus: an approach to therapy in this difficult clinical situation. Epilepsia. 2011;52:53-6.

10. Li Y, Tian L, Zeng T, Chen J, Chen L, Zhou D. Clinical features and outcome of superrefractory status epilepticus: a retrospective analysis in West China. Seizure. 2014;23:722-7.

11. Jayalakshmi S, Ruikar D, Vooturi S, Alladi S, Sahu S, Kaul S, et al. Determinants and predictors of outcome in super refractory status epilepticus - a developing country perspective. Epilepsy Res. 2014;108:1609-17.

12. Tian L, Li Y, Xue X, Wu M, Liu F, Hao X, et al. Super-refractory status epilepticus in West China. Acta Neurol Scand. 2015;132:1-6. should be performed to confirm 'burst-suppression' pattern. Anaesthetic weaning should then be performed slowly and at a stable rate along the following 24 hours. If SE recurs during or after thiopental weaning, another two trials should be performed under association of phenobarbital and then under ketamine sedation (which should be weaned thereafter). If SE still persists, progressively longer trials of sedation and weaning should be considered and alternative therapies associated.

\section{PROTECTION OF HUMANS AND ANIMALS}

The authors declare that the procedures were followed according to the regulations established by the Clinical Research and Ethics Committee and to the Helsinki Declaration of the World Medical Association.

\section{DATA CONFIDENTIALITY}

The authors declare having followed the protocols in use at their working center regarding patients' data publication.

\section{CONFLICTS OF INTEREST}

All authors report no conflict of interest.

\section{FUNDING SOURCES}

This work received no specific grant from any funding agency in the public, commercial, or not-for-profit sectors.

13. Smith KR, Kittler JT. The cell biology of synaptic inhibition in health and disease. Curr Opin Neurobiol. 2010;20:550-6.

14. Cock HR, Tong X, Hargreaves I, Heales SJ, Clark JP, Patsalos PN, et al. Mitochondrial dysfunction associated with neuronal death following status epilepticus in rat. Epilepsy Res. 2002;48:157-68.

15. Friedman A, Dingledine R. Molecular cascades that mediate the influence of inflammation on epilepsy. Epilepsia. 2011;52:33-9.

16. Tan RY, Neligan A, Shorvon SD. The uncommon causes of status epilepticus: a systematic review. Epilepsy Res. 2010;91:111-22.

17. Neligan A, Shorvon SD. Prognostic factors, morbidity and mortality in tonic-clonic status epilepticus: a review. Epilepsy Res. 2011;93:1-10.

18. Ferlisi M, Shorvon S. The outcome of therapies in refractory and superrefractory convulsive status epilepticus and recommendations for therapy. Brain. 2012;135:2314-28.

19. Claassen J, Hirsch LJ, Emerson RG, Mayer SA. Treatment of refractory status epilepticus with pentobarbital, propofol, or midazolam: a systematic review. Epilepsia. 2002;43:146-53.

20. Gaspard N, Foreman B, Judd LM, Brenton JN, Nathan BR, McCoy $\mathrm{BM}$, et al. Intravenous ketamine for the treatment of refractory status epilepticus: a retrospective multicenter study. Epilepsia. 2013;54:1498503.

21. Shorvon S, Ferlisi M. The treatment of super-refractory status epilepticus: a critical review of available therapies and a clinical treatment protocol. Brain. 2011;134:2802-18.

22. Rossetti AO, Bleck TP. What's new in status epilepticus? Intensive Care Med. 2014;40:1359-62.

23. Ubogu EE, Sagar SM, Lerner AJ, Maddux BN, Suarez J, Werz MA. Ketamine for refractory status epilepticus: a case of possible ketamineinduced neurotoxicity. Epilepsy Behav. 2003;4:70-5.

24. Paquette V, Culley C, Greanya ED, Ensom MH. Lacosamide as adjunctive therapy in refractory epilepsy in adults: a systematic review. Seizure. 2015;25:1-17.

25. Rohracher A, Höfler J, Kalss G, Leitinger M, Kuchukhidze G, Deak I, et al. Perampanel in patients with refractory and super-refractory status epilepticus in a neurological intensive care unit. Epilepsy Behav. 2015;49:354-8

26. Pugin D, Foreman B, De Marchis GM, Fernandez A, Schmidt JM, 
Czeisler BM, et al. Is pentobarbital safe and efficacious in the treatment of super-refractory status epilepticus: a cohort study. Crit Care. 2014; 18:R103.

27. Visser NA, Braun KP, Leijten FS, van Nieuwenhuizen O, Wokke JH, van den Bergh WM. Magnesium treatment for patients with refractory status epilepticus due to POLG1-mutations. J Neurol. 2011;258:218-22.

28. Friedman A, Dingledine R. Molecular cascades that mediate the influence of inflammation on epilepsy. Epilepsia. 2011;52:33-9.

29. Feuillet L, Guedj E, Laksiri N, Philip E, Habib G, Pelletier J, et al. Deep vein thrombosis after intravenous immunoglobulins associated with methylprednisolone. Thromb Haemost. 2004;92:662-5.

30. Schenone AL, Cohen A, Patarroyo G, Harper L, Wang X, Shishehbor $\mathrm{MH}$, et al. Therapeutic hypothermia after cardiac arrest: a systematic review/meta-analysis exploring the impact of expanded criteria and targeted temperature. Resuscitation. 2016;108:102-10

31. Bennett AE, Hoesch RE, DeWitt LD, Afra P, Ansari SA. Therapeutic hypothermia for status epilepticus: A report, historical perspective, and review. Clin Neurol Neurosurg. 2014;126:103-9.

32. Nabbout R, Mazzuca M, Hubert P, Peudennier S, Allaire C, Flurin V, et al. Efficacy of ketogenic diet in severe refractory status epilepticus initiating fever induced refractory epileptic encephalopathy in school age children (FIRES). Epilepsia. 2010;51:2033-7.

33. Thakur KT, Probasco JC, Hocker SE, Roehl K, Henry B, Kossoff EH, et al. Ketogenic diet for adults in super-refractory status epilepticus. Neurology. 2014;82:665-70.

34. van Delft R, Lambrechts D, Verschuure P, Hulsman J, Majoie M. Blood beta-hydroxybutyrate correlates better with seizure reduction due to ketogenic diet than do ketones in the urine. Seizure. 2010;19:36-9. 